Article

\title{
Daytime Variation of Urban Heat Islands: The Case Study of Doha, Qatar
}

\author{
Yasuyo Makido ${ }^{1,+}$, Vivek Shandas ${ }^{1, *, \dagger}$, Salim Ferwati ${ }^{2, \dagger}$ and David Sailor ${ }^{3,+}$ \\ 1 Toulan School of Urban Studies and Planning, Portland State University, 1825 SW Broadway, Portland, \\ OR 97201, USA; ymakido@pdx.edu \\ 2 Department of Architecture and Urban Planning, Qatar University, Al Tarfa, Doha 2713, Qatar; \\ sferwati@qu.edu.qa \\ 3 School of Geographical Sciences and Urban Planning, Arizona State University, 975 S Myrtle Ave., Tempe, \\ AZ 85281, USA; dsailor@asu.edu \\ * Correspondence: vshandas@pdx.edu; Tel.: +1-503-725-5222 \\ + These authors contributed equally to this work.
}

Academic Editors: Nir Y. Krakauer, Tarendra Lakhankar, Ajay K. Jha and Vishnu Pandey

Received: 30 April 2016; Accepted: 8 June 2016; Published: 16 June 2016

\begin{abstract}
Recent evidence suggests that urban forms and materials can help to mediate temporal variation of microclimates and that landscape modifications can potentially reduce temperatures and increase accessibility to outdoor environments. To understand the relationship between urban form and temperature moderation, we examined the spatial and temporal variation of air temperature throughout one desert city-Doha, Qatar-by conducting vehicle traverses using highly resolved temperature and GPS data logs to determine spatial differences in summertime air temperatures. To help explain near-surface air temperatures using land cover variables, we employed three statistical approaches: Ordinary Least Squares (OLS), Regression Tree Analysis (RTA), and Random Forest (RF). We validated the predictions of the statistical models by computing the Root Mean Square Error (RMSE) and discovered that temporal variations in urban heat are mediated by different factors throughout the day. The average RMSE for OLS, RTA and RF is 1.25, 0.96, and 0.65 (in Celsius), respectively, suggesting that the $\mathrm{RF}$ is the best model for predicting near-surface air temperatures at this study site. We conclude by recommending the features of the landscape that have the greatest potential for reducing extreme heat in arid climates.
\end{abstract}

Keywords: arid climate; urban heat island; spatial analysis; vehicle temperature traverse; random forest

\section{Introduction}

Outdoor daytime air temperatures in desert cities test the human body's ability to tolerate being outdoors throughout much of the year, yet desert cities are some of the most rapidly growing areas on the planet. The rapid rise in population, combined with extreme heat, increases the likelihood of communities suffering from respiratory illnesses, heat stroke, and cardiac failure [1,2]. Heat stress is, in fact, one of the leading weather-related causes of death in many parts of the globe [3,4]. Therefore, finding ways to reduce the intensity of urban heat stress, particularly in desert cities, poses an important challenge to public health, tourism, and the livability of cities in general.

Land surface characteristics directly relate to the surface the urban heat island (UHI) $[5,6]$. Recent evidence suggests that desert cities, unlike cities in temperate zones, often show a UHI effect, inverting the urban heat island phenomenon, with the result that specific urban areas appear colder than suburban areas during the daytime [7,8]. As a result, urban development patterns have the potential to reduce temperatures and increase accessibility to the outdoor environment through modifications 
to the built environment. Previous research in the arid desert cities of Phoenix, Dubai, and others suggests that a combination of vegetation, the presence of water, and landscape design all affect the thermal comfort of human inhabitants $[9,10]$.

While several emerging studies of desert cities have identified those landscape features that mediate urban heat, we currently lack the ability to describe differences in temperatures throughout the day, in part because earlier studies relied on remotely sensed descriptions of cities, which lack the ability to describe the diurnal profiles of temperature. Early studies using satellite imagery began decades ago with Rao [11], who examined surface urban heat islands from thermal infrared data. Since then, various sensor-platforms—-such as NOAA, AVHRR, Landsat MSS, TM, and ASTER-have been used to determine the urban thermal climate. More recently, land surface temperatures (LST) derived from thermal bands of radiometric instruments flown on satellites and high-altitude aircraft have been used to analyze the relationships among LST and landscape characteristics such as NDVI, NDBI, percent impervious surface, and percent vegetation by using linear regression [12,13], multiple linear regression [14], geographically-weighted regression [15] (Su et al., 2012), and correlation analysis [16]. These studies are helpful for refining UHI analysis, yet they still lack a temporal description, which limits our ability to understand which landscape factors drive (or ameliorate) localized heat stress throughout the day.

One approach to developing a temporal-based assessment of urban heat is to use ground-based empirical measures of temperature. One advantage to using ground-based measurements is the capacity to describe differences that individuals and communities directly experience. Oke [17] measured air temperature from car traverses in Vancouver, B.C. and claimed that heat island intensity is more directly related the physical structure of an urban area than its size. More recently, Hart and Sailor [18] employed tree-structured regression models to investigate the spatial variability of urban heat intensity using vehicle temperature traverse and GIS resources in Portland (Oregon, USA). Tree-structured regression models enable the determination of the most important land-use and surface variables affecting the UHI intensity of metropolitan areas. Later, Heusinkveld et al. [19] conducted bicycle traverse measurements to assess the spatial variation of temperature during a summer day in Rotterdam. They found that spatial variations in temperature were strongly affected by local vegetation cover. Using a ground-based approach and regression analysis, Yan et al. [20] found that localized land cover composition and site geometry were two of the most important variables affecting local air temperatures in Beijing. Further, Ho et al. [21] examined three statistical models by calibrating satellite-derived predictors such as LST and weather station data to map the daily maximum air temperature distribution in greater Vancouver. They found that the random forest model was the best among three statistical models used to map temperature distributions in the area. Finally, Yokobori and Ohta [22] used mobile traverses to conduct air temperature observations that would clarify the effect of land cover on ambient air temperatures in Tokyo. They found that an intra-urban heat island existed throughout the year, and they observed that air temperatures varied significantly according to ambient land cover types.

The use of ground-based and remote measurements of urban temperatures are a promising step toward better describing spatial variation; however, several questions still remain unaddressed. For example, satellite measurements can offer periodic descriptions of a city, yet temperatures vary throughout the day, and 'snap shots' of surface temperatures preclude an understanding of how those factors affect temporal variations in urban heat. While the land cover variables derived from the satellite images do not change throughout a day, we hypothesized that the effects of these variables will change throughout the day as temperatures change. In addition, it is unknown what techniques might allow for the higher predictability of urban heat in cities that have limited land use and land cover information available. To better understand the relationship between temperatures, diurnal cycles, and built environment factors, we examined the spatial and temporal variation of air temperatures throughout one city-Doha, Qatar. We addressed two research questions in this study: (1) which statistical models best explain the variability of urban heat? and (2) what land use and land cover 
factors best describe the variations in urban heat island effects throughout the day? To address these questions, we used a combination of ground-based, empirically-derived, mobile vehicle temperature traverses and land cover features that helped to populate three types of statistical models: ordinary least squares, regression trees, and random forests.

\section{Materials and Methods}

We used a cross-sectional research design to capture variations of near surface air temperatures (referred to as "air temperature" in this paper) throughout the day in Doha, Qatar. Numerous vehicle traverses were the primary means used to assess both spatial and temporal temperature variations in the study area. Based on these empirically-derived data, we developed statistical models to evaluate the extent to which specific land use variables helped to describe variations in temperature. We begin here by describing the vehicle traverses and land cover variables, which provide the context for subsequent descriptions of our statistical models.

\subsection{Vehicle Temperature Traverses}

Doha is one of the fastest growing cities in the Arabic world and is the largest city in Qatar (Figure 1). Since the late 1970s, Doha has changed after rapid urbanization and westernization, which have resulted in decreases in vegetation surfaces and increases in urban built-up areas. These developments, led by petro-urbanism, represent the largest urban explosion in Doha's history [23]. At the same time, according to the population influx of external and internal migrants, Doha is one of the busiest Arabic cities. According to census block data from 2013, the total population of Doha now exceeds 1.3 million.

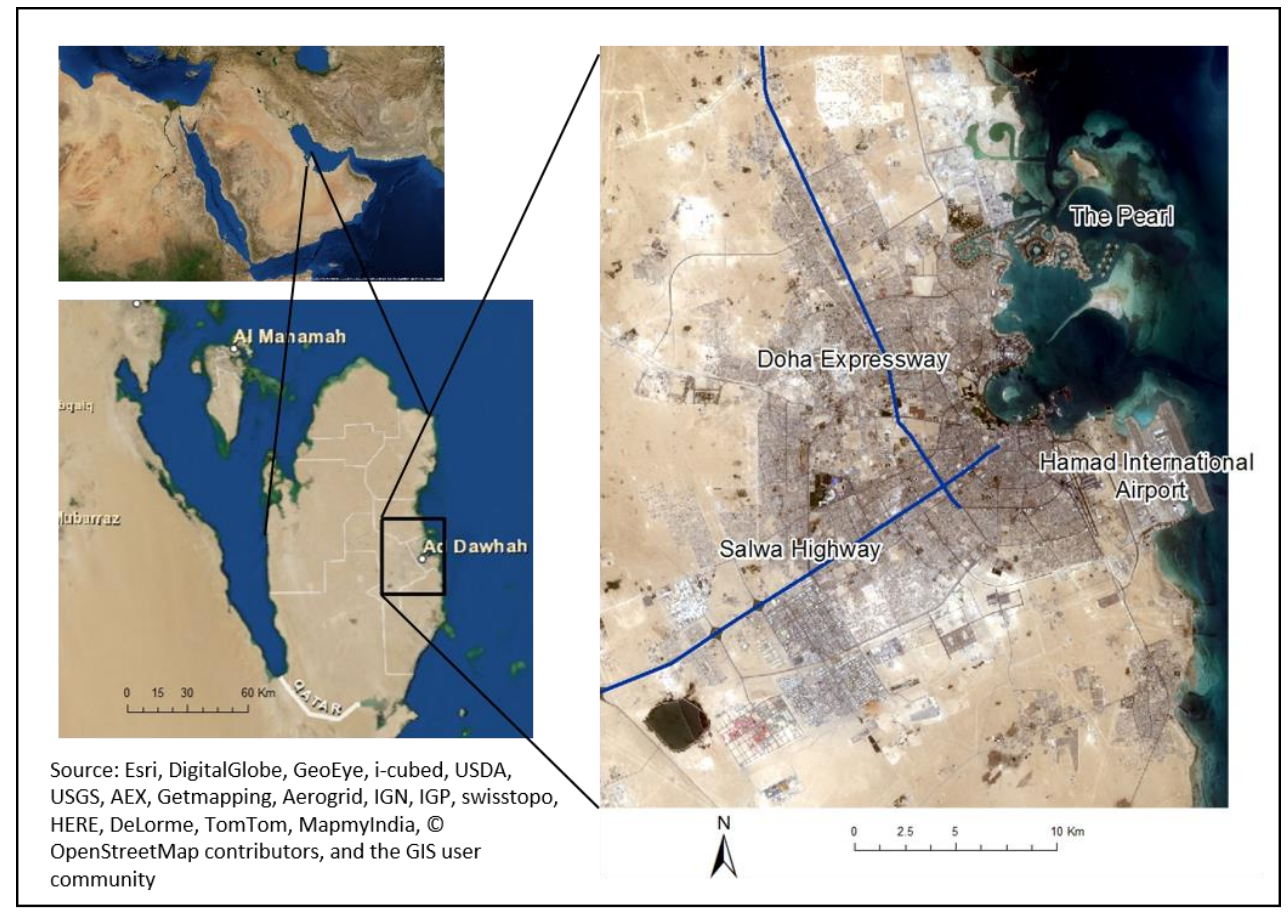

Figure 1. Doha study area.

The vehicle traverses examined in this study on 8 and 9 September in 2014 and 12, 14, and 15 May in 2015 covered all parts of the city of Doha (Figure 2). Following an established protocol [18], we used a Type T fine (30 gauge) thermocouple mounted in a $12 \mathrm{~cm}$ long, $2.5 \mathrm{~cm}$ diameter white plastic shade tube. The tube was supported approximately $25 \mathrm{~cm}$ above the vehicle roof on the passenger-side window (Figure 3). The temperature sensors were connected to data logging temperature recorders with an 
estimated system accuracy of \pm 0.5 Celsius and a $90 \%$ response time of less than $60 \mathrm{~s}$ at a $1 \mathrm{~m} / \mathrm{s}$ airflow. A time-synchronous GPS system was also attached to each car so that the temperature measurements (with a sampling frequency of $1 \mathrm{~s}$ in September 2014 and $10 \mathrm{~s}$ in May 2015) could be paired with a GPS location. Data for vehicle speeds of less than $5 \mathrm{~km} / \mathrm{h}$ were discarded as the temperature sensors were aspirated by the movement of the vehicle, and we aimed to avoid oversampling when the vehicles were stopped (e.g., in traffic or at traffic lights). Each day's traverse involved four cars, lasted one hour, and was conducted at three time periods: 6:00-7:00, 13:00-14:00, and 19:00-20:00. Each car traversed approximately $25-30 \mathrm{~km}$.

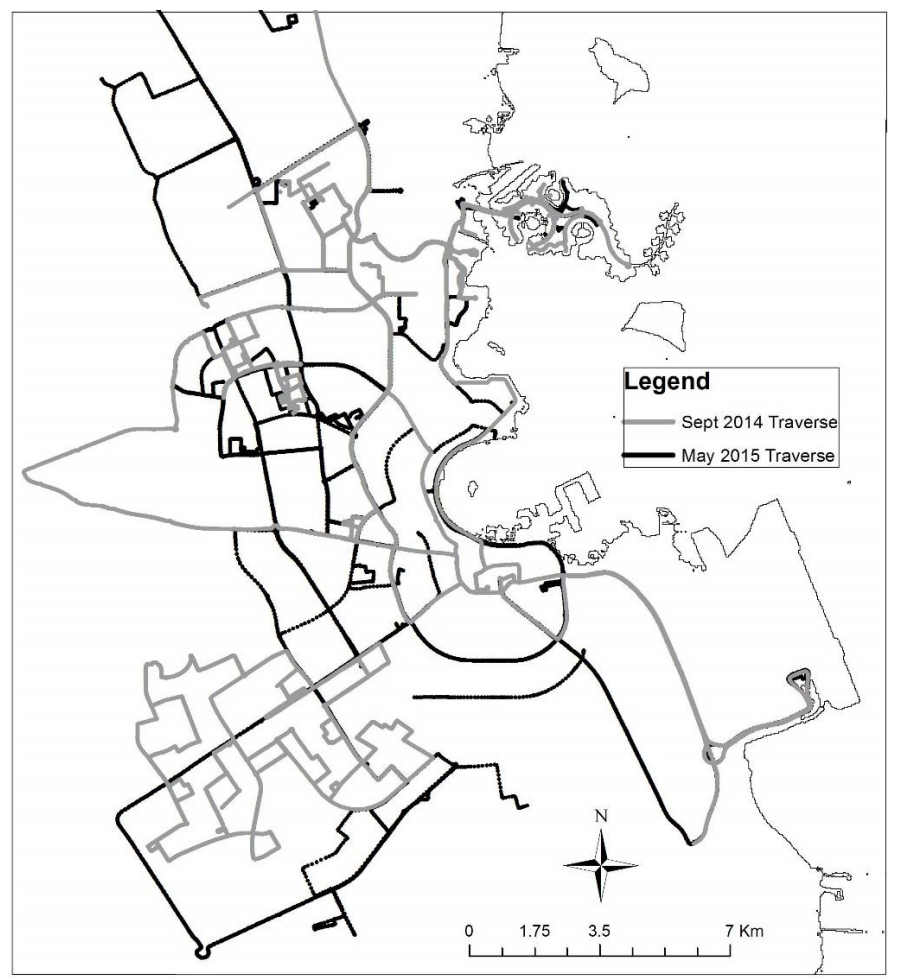

Figure 2. Vehicle temperature traverses across the study area, Doha. Coverage on 8 and 9 September 2014 and 12, 14, and 15 May 2015.

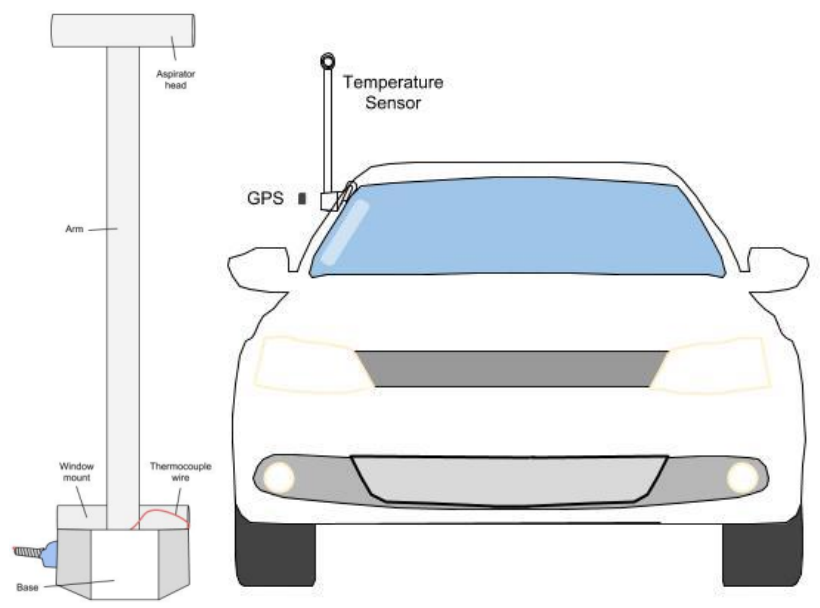

Figure 3. Temperature sensor mounted within plastic tube (Left) and vehicle with the plastic tube (Right). Image by Jackson Voelkel. 


\subsection{Land Use and Land Cover Variables}

We acquired 30-m resolution satellite sensor imagery from the US Geological Survey's Landsat OLI files taken on 12 September 2014 . The study area $(23.5 \mathrm{~km} \times 25.9 \mathrm{~km})$, which encompassed the Doha metropolitan region, was extracted from the scene of the satellite sensor imagery. All Landsat bands (visible, near, and shortwave infrared) except the thermal band were used in the classification process. For accuracy assessment, due to a lack of ground truth data at this study site, we used existing QuickBird $^{\mathrm{TM}}$ high-resolution imagery (acquisition date $=3$ April 2013). Since the acquisition dates of Landsat and QuickBird were separated by nearly one and a half years, we examined how the landscapes changed over time. We employed change detection analysis using two images: Landsat 2013 (acquisition date = 3 July 2013) and Landsat 2014 (acquisition date $=9$ December 2014). For this study, we examined two types of feature indices: Vegetation Index (NDVI, Equation (1)) [24] and Built-up Index (NDBI, Equation (2)) [25].

$$
\begin{aligned}
& \text { NDVI }=(\text { Band } 5-\text { Band } 4) /(\text { Band } 5+\text { Band } 4) \\
& \text { NDBI }=(\text { Band } 6-\text { Band } 5) /(\text { Band } 6+\text { Band } 5)
\end{aligned}
$$

The result of the change of detection analysis suggested that the change of vegetation and built-up areas occurred in less than $0.3 \%$ of the study area, which validated the QuickBird ${ }^{\mathrm{TM}}$ image as acceptable ground truth data. All image processing work and accuracy assessments were carried out in ENVI 5.1 (Exelis Visual Information Solutions, Boulder, CO, USA) and ArcGIS 10.2 (ESRI Inc., Redlands, CA, USA).

\subsubsection{Classification and Albedo}

In order to compensate for the lack of ancillary data at this study site, and based on the prior satellite-based research of the study area [26], we employed a simplified hybrid classification method [27]. Each image, with six bands, was sorted into 40 clusters using the ISODATA unsupervised classification method. Only homogeneous clusters were labeled into one of four categories: Urban, Vegetation, Soil, and Water (Table 1). Other clusters that exhibited mixed classes were clipped out from the image for further classification using supervised classification. The maximum likelihood algorithm, which evaluates both the variance and covariance of the category spectral response patterns when classifying an unknown pixel, was applied to the clipped images [28]. The images were initially classified into seven classes: Urban 1, Urban 2, Vegetation, Soil 1, Soil 2, Water1, and Water 2. Ten to 20 training sites for each class were selected with the aid of a panchromatic band and/or QuickBird ${ }^{\mathrm{TM}}$ imagery. The classified images were resampled to the aforementioned four classes and combined with the ISODATA classified land use/cover map.

Table 1. Land use/cover classes and definitions used in this study.

\begin{tabular}{ll}
\hline Classes & Definition \\
\hline Urban & All built-up surfaces, including roads, commercial, industrial pavements, and construction sites. \\
Vegetation & All areas of vegetation, including farms, parks golf courses, and lawns. \\
Soil & Bare and exposed rock, coastal sands, and sand dunes. \\
Water & All areas of open water, including lakes and the ocean. \\
\hline
\end{tabular}

Albedo was computed from visible and near infrared bands in Landsat 8 using Equation (3) [29]. For this equation, Liang's [30] formula to calculate Landsat shortwave albedo was normalized [31], 2010). Although this formula was developed for Landsat ETM+, it is applicable to Landsat OLI [32] as the band numbers were adjusted to conform to the OLI standard

$$
\alpha_{\text {short }}=\frac{0.356 \rho_{2}+0.130 \rho_{4}+0.373 \rho_{5}+0.085 \rho_{6}+0.072 \rho_{7}-0.0018}{0.356+0.130+0.373+0.085+0.072}
$$


where $\rho$ represents the Top of Atmosphere (TOA) reflectance of Landsat bands 2, 4, 5, 6, and 7. The resulting Digital Number was converted to TOA using the radiometric calibration tool in ENVI 5.1.

\subsubsection{Accuracy Assessment}

To address the lack of ground-level land use/land cover data, we conducted an accuracy assessment using high resolution satellite sensor imagery with half of the total images that we classified. To conduct an accuracy assessment of the Landsat images, the Quickbird ${ }^{\mathrm{TM}}$ imagery was ortho-rectified and pan-sharpened. Orthorectification is the correction of the image, pixel-by-pixel, for topographic distortion and results in every pixel appearing to be viewed from directly above [33]. Pan-sharpening, meanwhile, is a process of combining a lower resolution multispectral imagery with high resolution panchromatic imagery to create a high resolution color image. For this study, Gram-Schmidt Pan Sharpening [34] was applied to obtain 60-cm multispectral data. All images were georeferenced using 1st order polynomial transformation, and the overall root mean square errors were less than half a pixel.

We also used a standard confusion matrix method by randomly sampling approximately 240 points (about 60 points for each of the four classes) and laying those points over the QuickBird ${ }^{\mathrm{TM}}$ imagery. We categorized each point into one of the four classes by visually determining the dominant land cover types within $30 \times 30 \mathrm{~m}$ polygons that coincided with the Landsat imagery's pixel footprints. The categorized data were used as reference data and the matrix was created to compare the relationship between the reference data and the corresponding classified data (Table 2). The overall classification accuracy was $85.6 \%$ and the kappa coefficient was 0.81 , which is consistent with the standard minimum accuracy of 85 [35] Some of the 15\% misclassification consists of spectral differentiation between sand/soil and other urban features (e.g., roof tops and parking lots that consist of sand and/or soil).

Table 2. Confusion matrix of accuracy assessment of the land cover classification for 2014 .

\begin{tabular}{|c|c|c|c|c|c|c|c|}
\hline & & \multicolumn{5}{|c|}{ Reference Data } & \multirow{2}{*}{$\begin{array}{c}\text { User's Accuracy } \\
(\%)\end{array}$} \\
\hline & & Urban & Vegetation & Soil & Water & Total & \\
\hline \multirow{5}{*}{$\begin{array}{c}\text { Classified } \\
\text { Data }\end{array}$} & Urban & 63 & 1 & 4 & 0 & 68 & 92.7 \\
\hline & Vegetation & 8 & 47 & 4 & 0 & 59 & 79.7 \\
\hline & Soil & 7 & 1 & 52 & 0 & 60 & 86.7 \\
\hline & Water & 7 & 1 & 1 & 40 & 49 & 81.6 \\
\hline & Total & 85 & 50 & 61 & 40 & 236 & \\
\hline \multicolumn{2}{|c|}{ Producer's accuracy $(\%)$} & 74.1 & 94.0 & 85.3 & 100.0 & & \\
\hline
\end{tabular}

\subsection{Analysis}

Each 30-m pixel was further evaluated in terms of four additional land surface variables: urban/non-urban, vegetation/non-vegetation, distance to the coast, and albedo. Urban, Vegetation, and Water classes, which were derived through hybrid classification, were used for these variables. Based on Heusinkveld et al.'s [19] approach of using a linear regression correlation coefficient between urban temperature and greenery density as a function of pie-shaped distance (ArcMap 10.x, geostatistical analyst), we quantified the area of wind-induced influence on each of the land surface variables for each discrete temperature measurement. We did not find a directional effect on the correlation coefficient, so we employed a circular-shaped area (called a buffer) and tested buffer distances between $50 \mathrm{~m}$ and $600 \mathrm{~m}$ at $50 \mathrm{~m}$ increments. Based on the correlations found between buffer size and temperature, we selected the most influential buffer sizes for each date/time by determining the buffer distances with the largest positive or negative effects on temperatures (Table 3). The maximum buffer size of $600 \mathrm{~m}$ was selected based on previous studies, which commonly employed 
several hundred meters [36] and $500 \mathrm{~m} / 1000 \mathrm{~m}$ [37] as buffer distances. The land surface variables employed, and the strongest distance effects, were as follows:

- $\quad$ Mean albedo within a certain radius (a\#)

- Percentage of urban area within a certain radius (u\#)

- Percentage of vegetation cover within a certain radius (v\#)

- $\quad$ Distance to the coast (w_dist)

Table 3. Buffer sizes for each variable (in meters).

\begin{tabular}{|c|c|c|c|c|c|c|c|c|c|}
\hline & \multicolumn{3}{|c|}{8 September 2014} & \multicolumn{3}{|c|}{9 September 2014} & & & \\
\hline & $6 \mathrm{am}$ & $1 \mathrm{pm}$ & $7 \mathrm{pm}$ & $6 \mathrm{am}$ & $1 \mathrm{pm}$ & $7 \mathrm{pm}$ & & & \\
\hline Albedo & 50 & 400 & 150 & 50 & 400 & 50 & & & \\
\hline Urban & 500 & 600 & 600 & 600 & 600 & 600 & & & \\
\hline \multirow[t]{3}{*}{ Vegetation } & 100 & 400 & 150 & 50 & 350 & 150 & & & \\
\hline & \multicolumn{3}{|c|}{12 May 2015} & \multicolumn{3}{|c|}{14 Мay 2015} & \multicolumn{3}{|c|}{15 May 2015} \\
\hline & $6 \mathrm{am}$ & $1 \mathrm{pm}$ & $7 \mathrm{pm}$ & $6 \mathrm{am}$ & $1 \mathrm{pm}$ & $7 \mathrm{pm}$ & $6 \mathrm{am}$ & $1 \mathrm{pm}$ & $7 \mathrm{pm}$ \\
\hline Albedo & 150 & 600 & 600 & 50 & 400 & 600 & 50 & 600 & 200 \\
\hline Urban & 600 & 50 & 50 & 100 & 600 & 300 & 50 & 600 & 600 \\
\hline Vegetation & 50 & 300 & 600 & 600 & 100 & 200 & 50 & 600 & 600 \\
\hline
\end{tabular}

We employed three statistical approaches to model air temperatures using these relevant predictors: ordinary least squares (OLS), regression tree analysis (RTA), and random forest (RF). OLS is the most commonly employed approach to understand the strength of independent variables in order to explain dependent variables [12-14].

RTA offers an alternative technique for handling nonlinear relationships between the dependent variable and the predictive variables [38]. The RTA algorithm uses a set of independent variables to recursively split dependent variables into subsets, which maximizes the reduction in the residual sum of squares [39]. Based on conditional probabilities, the tree contains left and right nodes. In our case, the left node indicated that a condition was true and the right node indicated that it was false (Figure 4). The study area was divided into four to six categories based on the node criteria. The values at each terminating node were considered the mean temperature for that terminal node, and served as an input for the multiple linear regression model. Depending on the specific parameters of each pixel in the study area, the regression tree was constructed to predict the temperature of each pixel. The first terminating node indicated the highest explanatory power for determining urban heat. While the specific regression trees varied by time of day-for 12 May at 1 pm, for example, most of the variation of temperature was based on distance to coast - the regression tree analysis offered a visual and analytical approach to describing factors that affect local variations in temperature.

$\mathrm{RF}$, a machine learning technique, is one of the data mining methods designed to produce accurate predictions that do not overfit the data. In a random forest analysis, a group of regression trees is created using samples from the training data, which is called 'bagging.' Unlike a regression tree, a random forest tree splits each node by using the best of a randomly chosen subset at that node. For the regression, the average prediction for all trees are considered; for classification, predictions are considered the 'vote' for the most popular class among all trees [40-42]. RF has been used with satellite-derived predictors to map air temperature distributions [21,37]. We used RF to test variables for both selected buffer sizes and all buffer sizes. Based on preliminary studies, the number of variables randomly sampled as candidates at each split was set to 20 for all variables and, for selected variables, to four. We selected a total of 500 trees to be grown. We used the R statistical software [43] for OLS, an additional extension called "rpart" for the regression tree analysis [44] and "randomForest" for the random forest analysis [41]. 


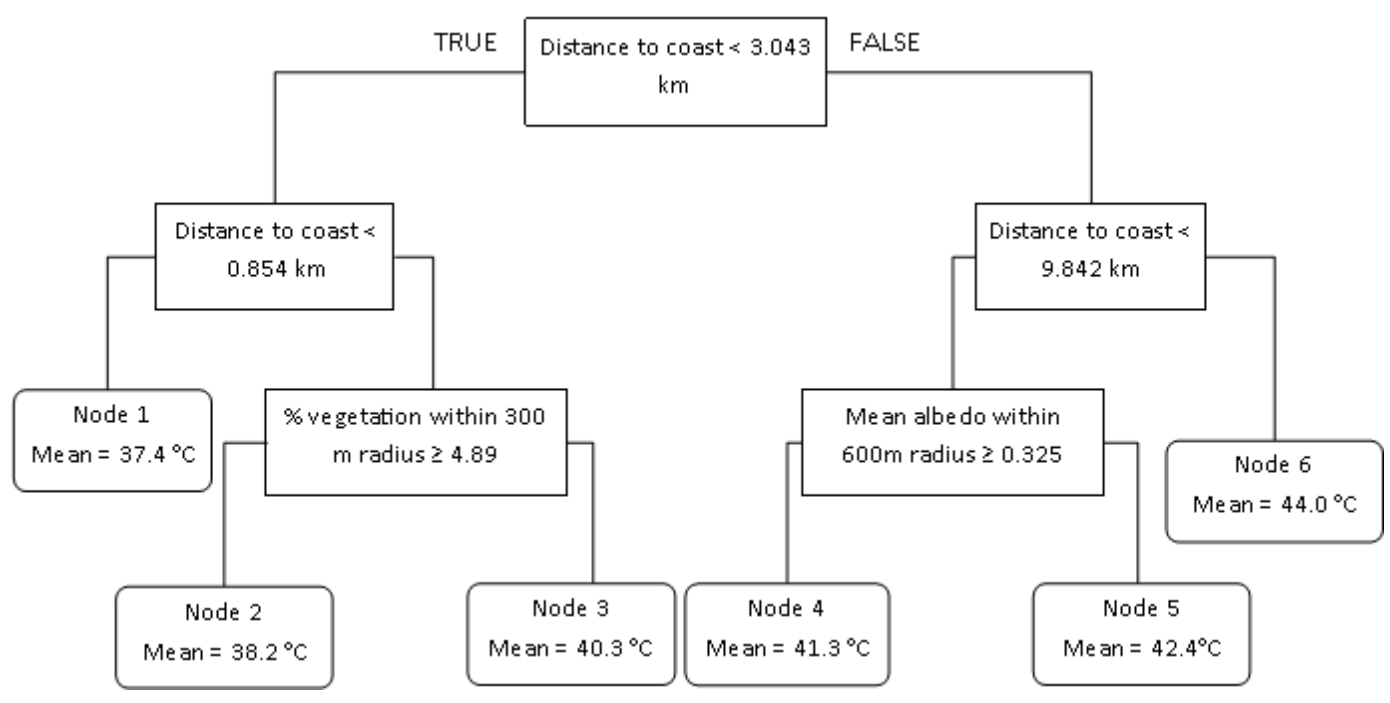

Figure 4. Example of Regression Tree Analysis with terminal nodes for 12 May 1 pm.

In order to compare the accuracy of each statistical model, we employed a 'holdout method,' which partitions the data into two mutually exclusive subsets called a training set and a test (i.e., holdout, set). Common applications of the holdout method suggest selecting $2 / 3$ of the data as the training set and the remaining $1 / 3$ as the test set [45]. For this study, we used $70 \%$ of the traverse data, randomly selected, as the training set and the remaining $30 \%$ of the data as the test set.

\section{Results and Discussion}

Using the results of the three models, we developed spatial descriptions of temperature variability for each date/time. The prediction of the air temperature map, using the three statistical models on the 12 May 2015, 1 pm vehicle traverse data, showed considerable variation in the results (Figure 5). Specifically, while all three models indicated a gradient of cooler to hotter moving inland, the OLS model seemed to generalize the differences while the random forest (RF) model indicated sharp contrast within smaller units across the study region. The regression tree analysis indicated a notable and sharp contrast, visible as 'rings' moving inland.
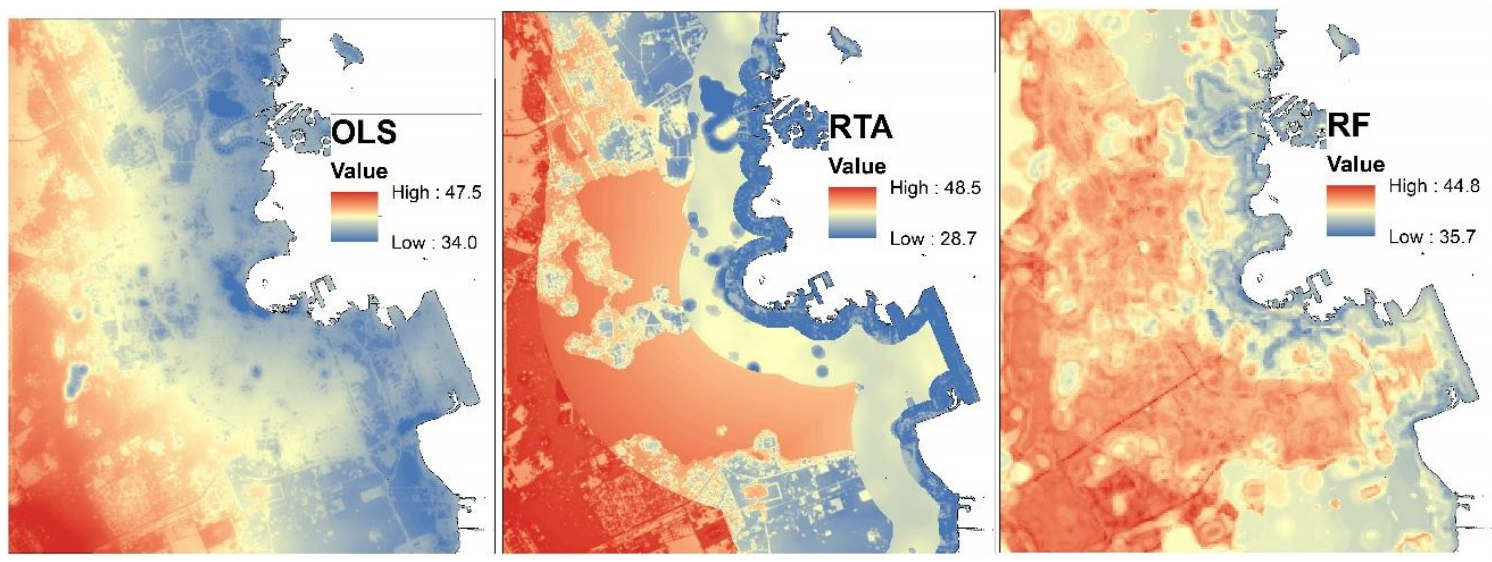

Figure 5. Predicted air temperature map (unit is in ${ }^{\circ} \mathrm{C}$ ) using OLS (left); Regression Tree (center); and Random Forest (right) for 12 May 2015, 1 pm.

We validated the models by computing the Root Mean Square Error (RMSE) between the predicted air temperatures and the measured air temperatures at $30 \%$ of the traverse points (Table 4 ). In all cases, 
RMSE was lower using RF than using RTA and OLS. This result suggested that the RF model more accurately predicted the surface temperatures than the other methods for this study site. Ho [21] also found that the RA model produced the lowest prediction errors for mapping urban air temperatures. For the RF model, the difference between using all buffers and using selected buffers was negligible. Therefore, we used all buffer sizes as input variables rather than selecting the most influential buffer sizes for all variables.

Table 4. Root Mean Square Error (RMSE) between predicted near-surface air temperatures and measured temperatures at the testing site (in Celsius).

\begin{tabular}{|c|c|c|c|c|c|c|c|c|c|}
\hline & \multicolumn{3}{|c|}{8 September 2014} & \multicolumn{3}{|c|}{9 September 2014} & & & \\
\hline & $6 \mathrm{am}$ & $1 \mathrm{pm}$ & 7 pm & $6 \mathrm{am}$ & $1 \mathrm{pm}$ & 7 pm & & & \\
\hline OLS & 1.28 & 1.21 & 0.62 & 0.96 & 1.22 & 0.63 & & & \\
\hline RTA & 1.05 & 1.09 & 0.53 & 0.80 & 1.06 & 0.57 & & & \\
\hline \multirow[t]{3}{*}{$\mathbf{R F}$} & 0.43 & 0.75 & 0.34 & 0.35 & 0.79 & 0.39 & & & \\
\hline & \multicolumn{3}{|c|}{12 May 2014} & \multicolumn{3}{|c|}{14 May 2014} & \multicolumn{3}{|c|}{15 May 2014} \\
\hline & $6 \mathrm{am}$ & $1 \mathrm{pm}$ & $7 \mathrm{pm}$ & $6 \mathrm{am}$ & $1 \mathrm{pm}$ & $7 \mathrm{pm}$ & $6 \mathrm{am}$ & $1 \mathrm{pm}$ & $7 \mathrm{pm}$ \\
\hline OLS & 1.19 & 1.81 & 1.72 & 1.44 & 2.71 & 0.96 & 0.79 & 1.15 & 1.00 \\
\hline RTA & 0.93 & 1.44 & 0.82 & 1.34 & 1.33 & 0.76 & 0.72 & 1.05 & 0.93 \\
\hline RF & 0.63 & 1.05 & 0.54 & 0.82 & 0.99 & 0.47 & 0.46 & 0.97 & 0.79 \\
\hline
\end{tabular}

We further assessed the important variables for predicting air temperature. Random Forest produces a measure of the importance of the predictor variable, which is called a mean decrease in accuracy. For each tree, the prediction error on the out-of-bag portion of the data is recorded, and the same is done after permuting each predictor variable. The difference between the two is then averaged over all trees and normalized by the standard deviation of the differences $[41,46]$. Table 5 lists the top three variables in terms of variable importance, and its value of the mean decreases in accuracy; a plus or minus sign shows whether the variable is positively or negatively related to temperature.

Table 5. Top three variables in terms of variable importance derived from RF. Each variable is described as follows: w_dist: distance to the coast, a: albedo, v: vegetation, u: urban, the number indicates the buffer distance.

\begin{tabular}{|c|c|c|c|c|c|c|c|c|c|c|}
\hline & \multicolumn{2}{|c|}{8 September 2014} & \multicolumn{2}{|c|}{9 September 2014} & \multicolumn{2}{|c|}{12 May 2015} & \multicolumn{2}{|c|}{14 May 2015} & \multicolumn{2}{|c|}{15 May 2015} \\
\hline \multirow{3}{*}{$6 \mathrm{am}$} & w_dist & 91.9 & w_dist & 104.6 & w_dist & 75.7 & w_dist & 61.0 & w_dist & 67.0 \\
\hline & a50 & 47.5 & v600 & 52.1 & u600 & 32.0 & a50 & 35.4 & v600 & 31.8 \\
\hline & v600 & 41.1 & v550 & 38.3 & v600 & 28.5 & $\mathrm{a} 600$ & 31.0 & $\mathrm{a} 600$ & 25.7 \\
\hline \multirow{3}{*}{$1 \mathrm{pm}$} & w_dist & 133.8 & w_dist & 134.0 & w_dist & 151.8 & w_dist & 63.4 & w_dist & 113.7 \\
\hline & v600 & 36.8 & $\mathrm{u} 200$ & 34.9 & a50 & 37.6 & v550 & 19.6 & a50 & 26.5 \\
\hline & a150 & 31.0 & u350 & 34.6 & a600 & 29.8 & a600 & 19.3 & v600 & 21.7 \\
\hline \multirow{3}{*}{$7 \mathrm{pm}$} & w_dist & 105.8 & w_dist & 129.2 & w_dist & 59.4 & w_dist & 105.9 & w_dist & 73.5 \\
\hline & $\mathrm{v} 600$ & 37.3 & $\mathrm{v} 600$ & 37.5 & $\mathrm{v} 600$ & 24.8 & $\mathrm{v} 550$ & 23.6 & $\mathrm{v} 600$ & 24.1 \\
\hline & a50 & 37.1 & a50 & 35.6 & v550 & 20.2 & v600 & 19.4 & v550 & 23.9 \\
\hline
\end{tabular}

Across the five days of our sample, we noted three important results. First, regardless of day or time, the distance to the coast is the most important predictor of temperature. Specifically, in the afternoon $(1 \mathrm{pm})$, the large value of the distance to the coast has its most significant impact on temperature. This is a result of the relative temperatures of the sea surface and land surface. Specifically, while daytime air temperatures on the land are in the range of 33 to $48^{\circ} \mathrm{C}$, the average sea surface temperature in the gulf during the summer is $33^{\circ} \mathrm{C}$ [47]. This temperature difference drives a sea breeze that provides local cooling near the coast. Although the prevailing wind in most months is from 
the North-Northwest in Doha, these winds are from the East and Northeast in summer. We acquired wind direction data from the weather station near Doha's city center, and the data supported this trend. Second, for five days in the evening $(7 \mathrm{pm})$, the second most important variable was measures of vegetation. Third, the results for the morning indicated the most inconsistency across five days for predicting the important variable. For example, the morning results indicated that the proximity to the water had both a cooling and heating effect, depending on the day. Overall, the results suggest that higher albedo corresponds to lower temperatures in the morning and evening, while farther distances from the coast result in higher temperatures in the afternoon and evening. Finally, more vegetation corresponds to lower temperatures in the evening.

Based on these results, we used the random forest model to divide the region into five categories, from the lowest (T1) to the highest temperatures (T5). By combining the time periods, we were able to identify those areas exhibiting the hottest temperatures (Figure 6). A visual description of the hottest areas in the morning show that they are near the central business district and at the Doha international airport, which is located near the southeast side of the coast. In the afternoon, the hottest areas are located furthest from the coast. In the evening, the hottest areas are located along two major highways, Salwa Road and Doha Expressway.

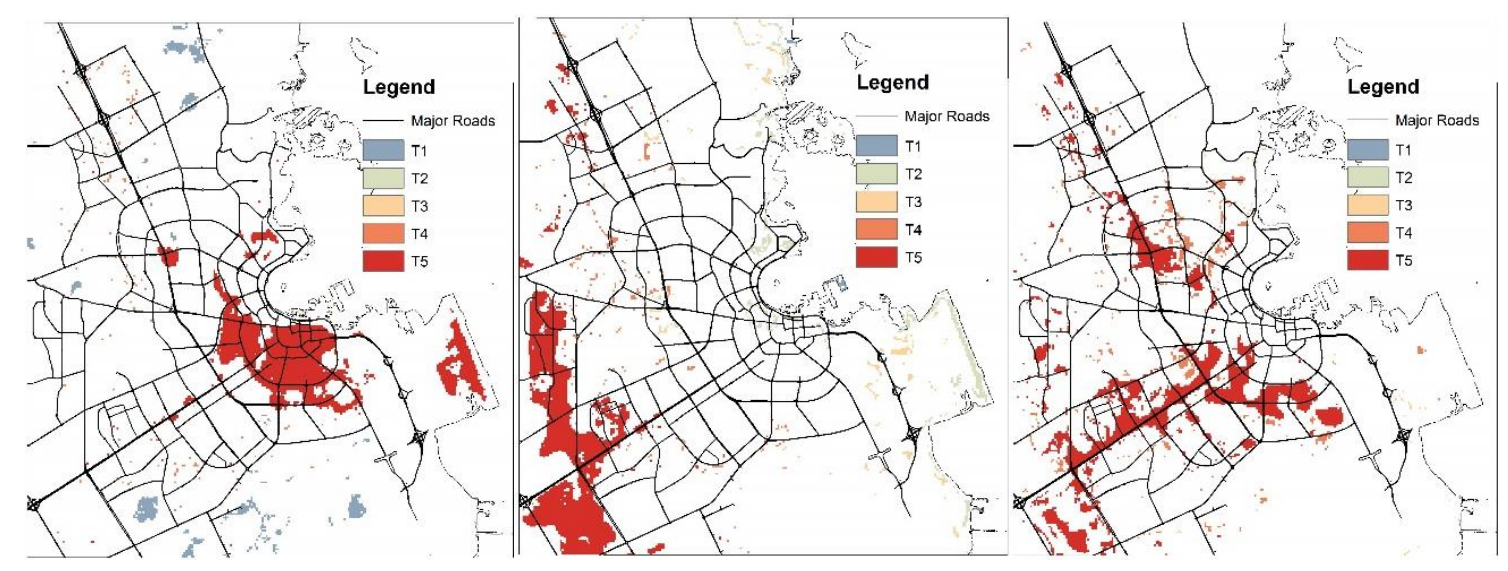

Figure 6. Air temperature variability maps with road maps for five days in each time period: 6 am (left); 1 pm (center); 7 pm (right).

\section{Conclusions}

The creation of impervious surfaces is centrally important to the creation of cities. In areas where high temperatures can cause major health impacts, understanding the role of landscape features is essential to developing mitigation strategies. Our analysis provides insight into the role of local land-cover and times of day in temperature variations across one city. Unlike earlier studies that suggest one urban heat island for a city, we were able to illustrate a dynamic description of urban heat effects throughout a day. Our empirical assessments, models, and predictions indicated that urban heat islands migrate throughout the day. This is the first such description of the phenomenon that we know of. We speculate that specific features of the landscape gain thermal capacity at different rates and also release temperatures at different rates. This results, our analysis suggests, in locations where such accumulations and dissipations of thermal difference occur.

These results suggest specific recommendations for future development in the region. While temperatures during the middle of the day may be intolerable for the human body, our results suggest that the interaction between land cover and temporal variation may lead to opportunities for reducing temperatures during "shoulder periods", which we define as transition times during late morning and early evenings, may offer chances for changing the urban design such that more people can spend time outside. If planning agencies are considering options for mediating temperatures to provide 
pedestrians greater access to outdoor spaces, then reducing the amount of urban area (a direct measure of impervious surfaces) may be a first step. While changing land cover may not be cost effective or a feasible option in places containing large amount of impervious surface, covering the concrete with trees may be a reasonable alternative. Despite the arid climate, given the abundant amount of water from desalination in Doha, water resources for expanding the urban canopy may be readily available. Of course, this solution raises other questions of sustainability related to desalination effects on the salinity of gulf waters. Ultimately, there will be tradeoffs between heat mitigation strategies and other environmental factors that must be thoroughly considered.

As expected, we found that the albedo was negatively related to local temperatures in the morning and evening. However, this relationship was positive during mid-day periods. Although increasing the albedo of surfaces is a common practice, one that could reduce the absorption of solar radiation, it might not work for Doha. Higher albedo could help the temperature in the morning and evening, but it could also have the adverse effect of increasing temperatures during the daytime. Finally, the distance from the coastline indicates that the mediating influence of coastal waters can significantly impact inland air temperatures. If, however, coastal winds are blocked by high-rise buildings along the coastline, inland areas may not benefit from this mediating influence. Restricting development along the coast, especially those buildings that prevent these coastal processes from meditating inland temperatures, is a policy that has traction in scholarly research [48], and it may be a policy option that can improve the short- and long-term quality of life of Doha's residents.

In this study, several methodological limitations that may obscure the implications of our findings. First, our study was designed as correlational and not causational. Therefore, we were only able to describe, in likelihood terms, the impact of different land cover factors on air temperatures. Second, the maximum buffer size was set to $600 \mathrm{~m}$, which was selected based on the existing literature [18] and our interest in identifying localized actions that could mitigate urban heat. The plot of the linear regression correlation coefficient between the buffer size and temperature for several variables, especially for the Urban class, did not reach a plateau by $600 \mathrm{~m}$. This indicated the possibility of a larger influential area. Reviewers have noted other studies indicating that land cover changes at distances $1 \mathrm{~km}$ from the monitoring site could impact air temperatures, and we expected to examine those relationships in future research. Finally, one of our research questions asked what land use and land cover factors best describe the variation of urban heat throughout the day. Since land use variables are generally not available to researchers in our study location, we only employed land cover factors. Accordingly, we were not able to discern the extent to which the urban form of different land uses (e.g., commercial, single family, residential, etc.) affects urban heat. Finally, as Nichol [49] found in a related study, satellite-derived surface temperatures are highly correlated to air temperatures. Our study did not include satellite-derived surface temperatures, and we believe that the accuracy of our models could be improved by adding relevant surface temperatures variables.

In future directions of this project, we expect to include satellite-derived surface temperatures, which will help us to understand the extent to which our techniques for assessing ambient temperatures can be enhanced through remotely-sensed satellite data. Such an approach will dramatically reduce the costs of conducting urban heat analysis for cities across the planet. Further, we were unable to evaluate the effectiveness of varying land cover modifications on ambient temperatures. In future work, we expect to expand these analyses by incorporating real and hypothesized changes into surface characteristics and materials. An emerging and promising literature suggests the need to provide context-specific applications for reducing urban heat, and we anticipate doing so in the near future.

The eventual outcome of the present project was to support decision-making efforts in order to improve livability in the ever-increasing outdoor temperatures of Doha. Several recent studies indicate that Doha and many other parts of the Middle East will encounter steady increases in daytime temperatures over the coming decades. Accordingly, our findings provide early evidence about the land cover factors that can hinder or amplify outdoor air temperatures. Difficult to find is information about how the local government is evaluating current mitigation options. Still needed are 
additional studies that attempt to integrate our findings about the physical characteristic of Doha with decision-making frameworks that may reduce harm caused by future increases in urban climates.

Acknowledgments: This paper was made possible by NPRP Grant No. NPRP 5-074-5-5015 from the Qatar National Research Fund (a member of Qatar Foundation). We are also grateful for Paul Pawlowski for his helpful suggestions, and careful reading and editing of the manuscript. The statements made herein are solely the responsibility of the authors.

Author Contributions: Yasuyo Makido was responsible for the geospatial analysis and development of the overall manuscript. Vivek Shandas contributed to the narrative and finalizing of the overall manuscript. David Sailor contributed to specific sections and provided feedback on the manuscript. Salim Ferwati contributed to specific sections and provided feedback on the manuscript.

Conflicts of Interest: The authors declare no conflict of interest.

\section{References}

1. Luber, G.; McGeehin, M. Climate change and extreme heat events. Am. J. Public Health 2008, 35, 429-435. [CrossRef] [PubMed]

2. Reid, C.E.; O’Neill, M.S.; Gronlund, C.J.; Brines, S.J.; Brown, D.G.; Diez-Roux, A.V.; Schwartz, J. Mapping community determinants of heat vulnerability. Environ. Health Perspect. 2009, 117, 1730. [CrossRef] [PubMed]

3. Knowlton, K. Projecting heat-related mortality impacts under a changing climate in the New York City region. Am. J. Public Health 2007, 97, 2028-2034. [CrossRef] [PubMed]

4. Balbus, J.M.; Malina, C. Identifying vulnerable subpopulations for climate change health effects in the United States. J. Occup. Environ. Med. 2009, 51, 33-37. [CrossRef] [PubMed]

5. Oke, T.R. The heat island of the urban boundary layer: Characteristics, causes and effects. In Wind Climate in Cities; Springer: Dordrecht, The Netherlands, 1995; pp. 81-107.

6. Voogt, J.A.; Oke, T.R. Thermal remote sensing of urban climates. Remote Sens. Environ. 2003, 86, 370-384. [CrossRef]

7. Lazzarini, M.; Marpu, P.R.; Ghedira, H. Temperature-land cover interactions: The inversion of urban heat island phenomenon in desert city areas. Remote Sens. Environ. 2013, 130, 136-152. [CrossRef]

8. Rasul, A.; Balzter, H.; Smith, C. Spatial variation of the daytime surface urban cool island during the dry season in Erbil, Iraqi Kurdistan, from Landsat 8. Urban Clim. 2015, 14, 176-186. [CrossRef]

9. Brazel, A.P.; Gober, S.-J.; Lee, S.; Grossman-Clarke, J.; Hedquist, Z.B.; Comparri, E. Determinants of changes in the regional urban heat island in metropolitan Phoenix (Arizona, USA) between 1990 and 2004. Clim. Res. 2007, 33, 171-182. [CrossRef]

10. Nassar, A.K.; Blackburn, G.A.; Whyatt, J.D. Developing the desert: The pace and process of urban growth in Dubai. Comput. Environ. Urban Syst. 2014, 45, 50-62. [CrossRef]

11. Rao, P.K. Remote sensing of urban heat islands from an environmental satellite. Bull. Am. Meteorol. Soc. 1972, 53, 647.

12. Yuan, F.; Bauer, M.E. Comparison of impervious surface area and normalized difference vegetation index as indicators of surface urban heat island effects in Landsat imagery. Remote Sens. Environ. 2007, 106, 375-386. [CrossRef]

13. Li, J.; Song, C.; Cao, L.; Zhu, F.; Meng, X.; Wu, J. Impacts of landscape structure on surface urban heat islands: A case study of Shanghai, China. Remote Sens. Environ. 2011, 115, 3249-3263. [CrossRef]

14. Frey, C.M.; Rigo, G.; Parlow, E. Urban radiation balance of two coastal cities in a hot and dry environment. Int. J. Remote Sens. 2007, 28, 2695-2712. [CrossRef]

15. Su, Y.F.; Foody, G.M.; Cheng, K.S. Spatial non-stationarity in the relationships between land cover and surface temperature in an urban heat island and its impacts on thermally sensitive populations. Landsc. Urban Plan. 2012, 107, 172-180. [CrossRef]

16. Zhou, W.; Qian, Y.; Li, X.; Li, W.; Han, L. Relationships between land cover and the surface urban heat island: Seasonal variability and effects of spatial and thematic resolution of land cover data on predicting land surface temperatures. Landsc. Ecol. 2014, 29, 153-167. [CrossRef]

17. Oke, T.R. The distinction between canopy and boundary-layer urban heat islands. Atmosphere 1976, 14, 268-277. 
18. Hart, M.A.; Sailor, D.J. Quantifying the influence of land-use and surface characteristics on spatial variability in the urban heat island. Theor. Appl. Climatol. 2009, 95, 397-406. [CrossRef]

19. Heusinkveld, B.G.; Steeneveld, G.J.; Hove, L.V.; Jacobs, C.M.J.; Holtslag, A.A.M. Spatial variability of the Rotterdam urban heat island as influenced by urban land use. J. Geophys. Res.: Atmos. 2014, 119, 677-692. [CrossRef]

20. Yan, H.; Fan, S.; Guo, C.; Wu, F.; Zhang, N.; Dong, L. Assessing the effects of landscape design parameters on intra-urban air temperature variability: The case of Beijing, China. Build. Environ. 2014, 76, 44-53. [CrossRef]

21. Ho, H.C.; Knudby, A.; Sirovyak, P.; Xu, Y.; Hodul, M.; Henderson, S.B. Mapping maximum urban air temperature on hot summer days. Remote Sens. Environ. 2014, 154, 38-45. [CrossRef]

22. Yokobori, T.; Ohta, S. Effect of land cover on air temperatures involved in the development of an intra-urban heat island. Clim. Res. 2016, 39, 61. [CrossRef]

23. Adham, K. Petro urbanism: The geo-politics of urban development in Doha, Qatar. Int. J. Hous. Sci. 2009, 33, $77-87$.

24. Jensen, J.R. Introductory Digital Image Processing; Prentice-Hall: Englewood Cliffs, NJ, USA, 1986.

25. Zha, Y.; Gao, J.; Ni, S. Use of normalized difference built-up index in automatically mapping urban areas from TM imagery. Int. J. Remote Sens. 2003, 24, 583-594. [CrossRef]

26. Shandas, V.; Makido, Y.; Hong, C.; Ferwati, S.; Sailor, D. Rapid urban growth and development patterns in the Middle East: The Case of Doha, Qatar. Unpublished work, 2016.

27. Lo, C.P.; Choi, J. A hybrid approach to urban land use/cover mapping using Landsat 7 Enhanced Thematic Mapper Plus (ETM+) images. Int. J. Remote Sens. 2004, 25, 2687-2700. [CrossRef]

28. Lillesand, T.; Kiefer, R.W.; Chipman, J. Remote Sensing and Image Interpretation; John Wiley \& Sons: New York, NY, USA, 2014.

29. YCEO. Yale Center for Earth Observation, How to Convert Landsat DNs to Albedo. Available online: http:/ /yceo.yale.edu/how-convert-landsat-dns-albedo (accessed on 20 April 2016).

30. Liang, S. Narrowband to broadband conversions of land surface albedo I: Algorithms. Remote Sens. Environ. 2001, 76, 213-238. [CrossRef]

31. Smith, R.B. The Heat Budget of the Earth s Surface Deduced from Space. Available online: http://yceo.yale. edu/sites/default/files/files/Surface_Heat_Budget_From_Space.pdf (accessed on 20 April 2016).

32. Yale University. Land Surface Properties, Regioanl Climate Feedbacks and Urban Adaptations. Available online: http://surfaceheat.sites.yale.edu/sites/default/files/Albedo.pdf (accessed on 20 April 2016).

33. Schowengerdt, R.A. Remote Sensing: Models and Methods for Image Processing, (No. 621.367 S476 1997); Academic Press: Boston, MA, USA, 1997.

34. Brower, B.V.; Laben, C.A. Process for Enhancing the Spatial Resolution of Multispectral Imagery Using Pansharpening. U.S. Patent 6,011,875, 4 January 2000.

35. Anderson, J.R.; Hardy, E.E.; Roach, J.T.; Witmer, R.E. A Land Use and Land Cover Classification System for Use with Remote Sensor Data; U.S. Government Printing Office (GPO): Washington, DC, USA, 1976.

36. Krüger, E.; Givoni, B. Outdoor measurements and temperature comparisons of seven monitoring stations: Preliminary studies in Curitiba, Brazil. Build. Environ. 2007, 42, 1685-1698. [CrossRef]

37. Ho, H.C.; Knudby, A.; Xu, Y.; Hodul, M.; Aminipouri, M. A comparison of urban heat islands mapped using skin temperature, air temperature, and apparent temperature (Humidex), for the greater Vancouver area. Sci. Total Environ. 2016, 544, 929-938. [CrossRef] [PubMed]

38. Yuan, F.; Wu, C.; Bauer, M.E. Comparison of spectral analysis techniques for impervious surface estimation using Landsat imagery. Photogramm. Eng. Remote Sens. 2008, 74, 1045-1055. [CrossRef]

39. Hansen, M.C.; DeFries, R.S.; Townshend, J.R.G.; Sohlberg, R.; Dimiceli, C.; Carroll, M. Towards an operational MODIS continuous field of percent tree cover algorithm: Examples using AVHRR and MODIS data. Remote Sens. Environ. 2002, 83, 303-319. [CrossRef]

40. Breiman, L. Random forests. Mach. Learn. 2001, 45, 5-32. [CrossRef]

41. Liaw, A.; Wiener, M. Classification and regression by randomForest. R News 2002, 2, 18-22.

42. Prasad, A.M.; Iverson, L.R.; Liaw, A. Newer classification and regression tree techniques: Bagging and random forests for ecological prediction. Ecosystems 2006, 9, 181-199. [CrossRef]

43. R Development Core Team. R: A Language and Environment for Statistical Computing. The R Foundation for Statistical Computing: Vienna, Austria. Available online: http://www.R-project.org/ (accessed on 20 April 2016). 
44. Therneau, T.; Atkinson, B.; Ripley, B.; Ripley, M.B. Package "rpart". Available online: cran.ma.ic.ac.uk/web/ packages/rpart/rpart.pdf (accessed on 20 April 2016).

45. Kohavi, R. A study of cross-validation and bootstrap for accuracy estimation and model selection. IJCAI 1995, 14, 1137-1145.

46. Breiman, L. RandomForest: Breiman and Cutler's Random Forests for Classification and Regression. Available online: https://www.stat.berkeley.edu/ breiman/RandomForests/ (accessed on 20 April 2016).

47. World sea temperature. Doha average August sea temperature. Available online: http://www. seatemperature.org/middle-east/qatar/doha-august.htm (accessed on 20 April 2016).

48. Wong, M.S.; Nichol, J.; Ng, E. A study of the "wall effect" caused by proliferation of high-rise buildings using GIS techniques. Landsc. Urban Plan. 2011, 102, 245-253. [CrossRef]

49. Nichol, J. Remote sensing of urban heat islands by day and night. Photogramm. Eng. Remote Sens. 2005, 71, 613-621. [CrossRef]

(C) 2016 by the authors; licensee MDPI, Basel, Switzerland. This article is an open access article distributed under the terms and conditions of the Creative Commons Attribution (CC-BY) license (http:/ / creativecommons.org/licenses/by/4.0/). 